\title{
Course in Psychiatry for Family Doctors
}

Francis Creed, Senior Lecturer in Psychiatry, Manchester Royal Infirmary, Oxford Road, Manchester

This course was organised so that future general practitioners might learn those aspects of psychiatry which are relevant to their future work. It has been recognised that six months working in a mental hospital is only helpful to the future GP in terms of assessment and treatment of severe psychiatric illness of which the general practitioner sees relatively little. ${ }^{1}$ The vast majority of psychiatric illness seen by a general practitioner in his day-to-day work is not represented at all in an in-patient psychiatric unit.

Although the course was held in the Department of Psychiatry, its form and content were designed to reflect the work of general practitioners. As we were heavily influenced by Professor Lesser ${ }^{2}$ the emphasis was on problem-orientated methods relevant to general practice and group discussion of the trainees' own work.

There is a fundamental organisational difficulty with such a course. Funding from the relevant Health Authority is available for those GP trainees who are doing an SHO post in psychiatry but no Health Authority funding is available for those trainees who do not hold such an SHO post.

The course has been held twice. On the second occasion we were fortunate to obtain funding from the medical liaison division of Upjohn Ltd for five GP trainees in their general practice year.

\section{Format of the course}

There are several aspects which we have considered to be essential in order to make this course successful. Firstly, the lecturers themselves have mostly been involved with research or clinical work in general practice. Secondly, we have used for lectures and seminars clinical material from the GP's surgery. Thirdly, all participants on the course made videotaped interviews for interview skills training.

Each day of the course was divided into four sessions:

\section{(1) Lecture/discussion}

The topics covered in these sessions were as follows: Somatic presentation/detection of psychiatric illness; anxiety and depression; physical illness and psychiatric morbidity; marital problems; major psychiatric illness in GP setting; sexual problems; childhood disorders; the confused elderly patient.

Each lecture commenced with a case presentation based where possible on a videotaped recording of an actual interview in a GP's surgery. These videotapes were available to us as a result of recordings being made of GP trainees in their surgery as part of a research project being performed in the Department. It was therefore possible to select interviews that were relevant to the topic in question for that date.

\section{(2) Case conference}

During the first course the participants attended a new type of case conference which had just started in this department. These conferences are addressed to management problems primarily and once a month are concerned with cases from the general medical and surgical units. It was intended that these case conferences would have more material relevant to future GPs than the conventional diagnostic ones. The feedback from the first course indicated that we were not successful in this aim.

For the second course we held a specially designed case conference at which the trainees presented cases and there were present both GPs and psychiatrists to discuss the problems brought up by the case. These were most appreciated when the psychiatrist and GP had both been involved in the patients' management. On those weeks when none of the GPs was available the session often discussed interview skills based on the videotaped interview brought by the trainee presenting the case.

\section{(3) Seminar}

The following topics were covered in the first hour of the afternoon:

The problem-based interview for family doctors; management of suicidal patients; ${ }^{*}$ bereavement counselling; problems related to alcohol; different types of psychotherapy;* psychiatric problems, pregnancy and childbirth; implications of clinical decisions; problems of drug abuse.

The sessions marked with an asterisk used role-playing as a form of instruction in the first course, but were dropped in the second course. The session of implications of clinical decisions used videotapes, with the trainees interviewing a role-played patient.

\section{(4) Interview skills training}

The last hour of the afternoon was spent in an interview skills training session with the trainees bringing recorded interviews that they had held with their own patients.

During the first course audiotapes were used for convenience but the videotaped interviews used in the second course were far superior. This training was performed in groups of five to six trainees to give everyone the opportunity to have at least one tape discussed.

\section{Response to the course}

The feedback from both occasions indicated that the trainees were very enthusiastic about this course. All lecture topics were rated as essential or relevant to their future work as general practitioners, and the quality of the lectures was rated highly. The trainees felt that there were no 
important omissions from the content of the course but suggested minor additions which mostly concerned clinical work in general practice.

After the first course the trainees commented that the videotaped interview sessions were more helpful than the audiotaped ones. They were rather unenthusiastic about role-play and some commented this form of teaching is only useful in a longer course where greater group cohesion develops. They felt that many of the case conferences were concerned with aspects of management which are relevant to psychiatrists but not general practitioners.

But the most striking criticism of the first course was the absence of trainees who were working in a general practice setting at the time. Since most of the course participants had not worked in general practice they felt it was relevant to their future needs but could only be really valuable if it emphasised more clearly the nature of work in the general practice setting where constraints of time and the type of work are quite different from a hospital SHO post in psychiatry.

For the second course we were most fortunate to have five places funded by the Medical Liaison Division of Upjohn Ltd. This meant that in the case conferences and interview skills training sessions videotapes of doctorpatient interactions in the GP's surgery were often used. The feedback from this course emphasised again the importance of trainees during their practice year. The interview skills training using videotapes were rated as excellent or very useful by $90 \%$ of the course participants and many requested a longer day and/or a longer course. The case conferences were most appreciated when there was a joint GP/psychiatrist presentation.

\section{Conchuion}

The feedback from many trainees indicated that they thought all GP trainees should attend such a course. It seems that this course covers areas of instruction which are not covered elsewhere and especially not in the experience provided by an SHO job in psychiatry. Other departments which have appropriate teachers, close links with local general practitioners and can provide videotaped interview skills training may be able to provide similar courses. But this training will not become widespread until the administrative difficulties of financing trainees in their general practice year have been overcome.

\section{Notes on the Dynamics of Medical Student Teaching and Implications for Future Medical Practice}

J. WiLson, Consultant Psychiatrist with a special interest in Psychotherapy, Henderson Hospital and Sutton Hospital, Surrey (formerly Registrar in Psychotherapy, St George's Hospital and Henderson Hospital)

I have recently addressed myself to the problems of teaching medical students. In my case it is that of teaching the principles of psychotherapy. It is difficult to teach about the doctor-patient relationship in the normally accepted lecture form. Definitions of transference, psychological defence mechanisms or empathy can be given, but this gives no impression of what is meant at an experiential level.

I would like to describe an experiential group which I conducted with medical students. This is not just to describe and explore the value of this method of teaching but to discuss the implications of the issues which were raised in the group. This is because they have important implications for the teaching of medical students and the effect this has on their future medical practice.

The group consisted of nine medical students and myself as conductor. We met on five consecutive weeks-for an hour on the first four weeks and two hours on the fifth week. The extra time on the fifth week was not intentional but arose out of an anomaly in the way the time had been allocated. A number of themes came up during the course of the group, which was free-floating with no set agenda. For the purpose of this discussion, I would like to give some impression of how the group went and also concentrate on one or two of the main issues which arose.

It would be reasonable to expect, and this indeed happened, that the students began by expressing feelings about being taught by an experiential method rather than the more normal didactic approach. This led to a discussion about how to deal with the situation. They tried ignoring the conductor, selecting one of the members of the group to act as 'the patient' and attempting to 'laugh it off. This produced discussion at a superficial level of the nature of the therapist/client relationship. How do you deal with the 'patient role', was one question asked. Were they being treated as patients by me anyway, was another. It seemed at times confusing for them but it also opened up rich areas for discussion. 